\title{
Serum Lipid as a Risk Factor of Ischaemic Stroke in Bangladeshi People
}

\author{
AKM FAZLUL HAQUE ${ }^{1}$, QUAZI TARIKUL ISLAM ${ }^{2}$, MD. KHALILUR RAHMAN ${ }^{3}$, MOHAMMAD HASSAN TARIK ${ }^{4}$, SURAYA \\ AHMED $^{5}$, APRNA DAS 6
}

\begin{abstract}
:
Background: The incidence of cerebrovascular disease increases with age and the number of stroke is projected to increase as the elderly population grows. With the advancement of the health status of the Bangladeshi people gradually the segment of elderly populations is increasing and thereby inviting many diseases which are due to aging process. Stroke occurs when blood vessels that carry blood to the brain suddenly blocked or burst, preventing blood flow to the brain. The most common cause of blood vessel blockages are thrombosis (a blood clot) or an embolism (floating clot). Blood clots may form in the arteries that are damaged by atherosclerosis. Atherosclerosis is an aging process but some factors (risk factor) precipitate it to occur earlier.

To find out the risk factors properly are of tremendous importance as risk factor change could directly influence or indirectly affect case fatality by altering the natural history of the disease. Serum lipids are thought to interact with the pathogenesis of stroke through atherosclerotic mechanism. As we the Bangladeshi people lives on rice mainly which is a carbohydrate food and we also usually do not practice regular exercise, so, though there is no clear statistical data but it can be presumed that serum lipids (cholesterol and triglyceride) of our people may be relatively in higher range and consequently we are gradually progressing to suffer from this fatal disease.
\end{abstract}

Objectives: To identify the high serum lipid as an independent risk factor of stroke.

Methods: This is a hospital based case-control study. Fifty (50) cases of stroke patients and age, sex matched 50 healthy control subjects were enrolled by non-random sampling. 12 hours fasting plasma lipids were estimated in both cases and control subjects. Then it was compared between cases and controls.

Results: Hypercholesterolemia (raise of serum total cholesterol) was higher in case group than control (mean value 206 \& $195.2 \mathrm{mg} / \mathrm{dl}$ respectively) but not statistically significant (>0.05). Mean LDL- cholesterol and triglycerides were significantly $(P<0.05)$ higher in case group than control group $(130.0 \mathrm{mg} / \mathrm{dl}$, to $106.3 \mathrm{mg} / \mathrm{dl} \& 230.7 \mathrm{mg} / \mathrm{dl}$, to $173.9 \mathrm{mg} / \mathrm{dl}$ respectively). Mean value of serum HDL-cholesterol was not significantly lower is case group than control group (44.68 \& $45.5 \mathrm{mg} / \mathrm{dl}$ respectively).

Conclusion: Serum lipids are significantly higher in ischaemic stroke patients than control group (LDL cholesterol and triglyceride). So, it may be an independent risk factor of ischeamic stroke.

Keyword: Ischaemic Stroke, Hypercholesterolaemia, Risk, Bangladesh.

\section{Introduction:}

Stroke is a disease of neurologic mortality and disability. The incidence of cerebrovascular diseases increases with age and the number of stroke is projected to increase as the elderly population grows, with a doubling in stroke death in the United States by $2030^{1}$. Similarly, gradually the segment of elderly population is increasing in Bangladesh and so inviting many diseases, which are due to aging process ${ }^{2}$.

Stroke can be divided into two major categories based on whether the disrupted blood supply to the brain is caused by the blocked blood vessel (known as ischaemic stroke)or a burst blood vessel (known as haemorrhagic stroke) ${ }^{3}$.
The most common causes of blood vessel blockages are thrombosis (a blood clot) or an embolism (floating clot). Blood clots may form in arteries that are damaged by atherosclerosis (also known as hardening of the arteries) ${ }^{2}$.

We know that the incidence of stroke increases with age. Atherosclerosis is also an aging process but some factors precipitate it to occur earlier ${ }^{4}$. These some factors are known as risk factors. To know and find out the risk factors properly are of tremendous importance as risk factor change could directly influence of indirectly affect case fatality by altering the natural history of the disease ${ }^{2}$.

1. Assistant Professor, Department of Medicine, Mymensingh Medical College, Mymensingh

2. Professor of Medicine, Dhaka Medical College, Dhaka.

3. Assistant Professor of Medicine, Rajshahi Medical College, Rajshahi.

4. Assistant Professor of Medicine, Rajshahi Medical College, Rajshahi.

5. Junior Consultant (Gynae), Upazila Health Complex, Keranigonj, Dhaka.

6. Assistant Professor of Medicine, Dhaka Medical College Hospital.

Correspondence: Dr. A.K.M. Fazlul Haque, Assistant Professor, Department of Medicine, Mymensingh Medical College, Mymensingh E-mail:akmfhaque60@yahoo.com 
Certain risk factors like age, sex and genetic factors are the definite and non-modifiable factors, but blood pressure, smoking, diabetes mellitus, heart disease, stenosis of precerebral arteries and transient ischaemic attacks (TIA) and alcohol are the definite modifiable risk factors; and lipids, fibrinogen and haematocrit, obesity, female sexual hormones are the probable risk factors for stroke $\mathrm{e}^{5}$.

The relation between serum lipids and ischemic stroke remain controversial. Studies of lipids related risk factors in cerebrovascular disease have varied greatly in their findings and also in their definition of cerebrovascular end points. Serum lipids are thought to interact with the pathogenesis of stroke through an atherosclerotic machanisms ${ }^{5}$. Besides these there is mounting epidemiologic evidence to support the relationship of lipid as a risk factor for ischaemic stroke ${ }^{6}$.

In the process of atherosclerosis dyslipidaemia (hypercholesterolaemia and hypertriglyceridaemia) plays major role through the formation of fibrofatty intimal plaque on the arterial wall (deposition of cholesterol and cholesterylester from the plasma protein into the arterial wall). The risk is correlated with the level of serum low density lipoprotein (LDL), formed from the catabolism of very low density lipoprotein (VLDL). LDL carries $70 \%$ of total serum cholesterol. Risk is inversely related to the HDL level, perhaps because HDL helps clear cholesterol from vessel wall lesion ${ }^{7}$.

Cholesterol is present in tissues and plasma as free cholesterol or as a storage form, combined with a long chain fatty acid as cholesteryl esters. In plasma both forms are transported in lipoproteins. A little more than half the cholesterol of the body arises by synthesis (almost 70\%) \& remainder is provided by the average diet. Plasma LDL is the vehicle of uptake of cholesterol and cholesteryl esters into many tissues. Free cholesterol is removed from the body either unchanged or after conversion to bile acid in the process known as reverse cholesterol transport ${ }^{8}$.

Triglycerides (triacylglycerol) are found in fat. It is an important constituent of other blood lipids (triacylglycerol$16 \%$, phospholipid- $30 \%$, cholesterol- $14 \%$, cholesteryl esters$36 \%$ and free fattyacid- $4 \%$ ). They are formed from the digestion of fats in food and from the synthesis within the liver from acetyl-co A, derived mainly from carbohydrates and uptake of free fatty acid from the circulation (lipogenesis from carbohydrate) $)^{8}$.

However, recent data also have affirmed the primary role of triglycerides in the genesis of atherosclerosis. This process involves the overabundance of triglyceride- rich lipoprotein particles, which paradoxically, can be enriched with cholesterol through the action of cholesterol ester transfer protein. These particles appear to be specially atherogenic. Also, low-density lipoproteins become smaller and denser-small, dense phenotype or pattern B- in hypertriglyceridemia states 9 .

Several proposed connection appear to exist between hypertriglyceridemia and atherosclerosis including the inverse corelation between triglyceride and HDL. The presumed atherogenicity of triglyceriderich liproprotein remnant particles, the potential resultant increase in the serum concentration and atherogenicity of low density of lipoprotein (LDL) and proposed interaction between serum triglyceride and fibrinolytic/coagulation systems ${ }^{10}$.

We know that triglycerides are the neutral fat synthesized from carbohydrate for storage in adipose tissue; i.e. excess carbohydrate, which is not utilized by the body, was stored in the adipose tissue as a depot fat ${ }^{11}$.

Most of our Bangladeshi people lives on rice mainly which is a carbohydrate food and they usually don't practice regular exercise, so, though there is no clear statistical data, but it can be presumed that serum cholesterol and serum triglycerides level of our people may be relatively in higher range. The main goal of this prospective study is to find out the relative risk of stroke in Bangladeshi people, who have dyslipidaemia.

\section{Materials and Methods:}

In this hospital based case control study 50 cases with ischemic stroke and 50 age and sex matched controls without stroke were selected on the basis of their clinical and CT scan of brain findings from Rajshahi Medical College Hospital through the convenient sampling during the period of March 2006 to October 2006. All the study subjects were free from heart disease (Myocardial infarctious, congenital heart disease, valvular heart disease with or without atrial fibrillations), diabetes mellitus, previous history of transient ischemic attack (TIA) or any case history of hemorrhagic stroke. Informed written consent were taken from all study subject prior to their enrollment. For all study subjects preformed questionnaires were used to collect data. Blood samples were collected aseptically from all study subjects after 12 hours fasting for the measurement of fasting lipid profile. Blood sample of the cases (stroke patients) were collected within 48 hours of the attack to avoid the effect of stroke and hospital diet on lipid profile 4 .

Data were analyzed using SPSS 2005. To find out the statistical significance paired ' $\mathrm{t}$ ' test was done and $\mathrm{P}$ value $<0.05$ was considered as statistically significant.

\section{Result:}

In this case control study 50 diagnosed ischaemic stroke cases (male-29 \& female-21) with mean age 53.6 years (age range 41-80 years) and 50 healthy control subjects (male-30, female-20) with mean age 56.7 years (age range $41-80$ years) were enrolled (Table-I). In the stroke patient's median plasma total cholesterol concentration was $206 \mathrm{mg} / \mathrm{dl}$ with a range $154.5-320 \mathrm{mg} / \mathrm{dl}$ and in control subject it was found to be $195.2 \mathrm{mg} / \mathrm{dl}$. with the range of $152-298.5 \mathrm{mg} / \mathrm{dl}$. Paired T test shows that the plasma concentration of total serum cholesterol was not significantly higher $(\mathrm{P}>.05)$ in case group than control subjects (Table-II). But mean LDL cholesterol 
Table-I

Age and Sex distributions of study subjects

\begin{tabular}{lccccc}
\hline Subject & Total number & Mean Age (yr) & Age range (yr.) & Male & Female \\
\hline Cases (Ischemic stroke patient) & 50 & 53.6 & $41-80$ & 29 & 21 \\
Control (without any stroke) & 50 & 56.7 & $41-80$ & 30 & 20 \\
\hline
\end{tabular}

Table-II

Comparison of Plasma lipids value between cases and control

\begin{tabular}{lccccc}
\hline Plasma lipid (mg/dl) & \multicolumn{2}{c}{ Cases } & \multicolumn{2}{c}{ Subjects } & \multicolumn{2}{c}{ Control } & \multicolumn{2}{c}{ Level of } \\
& Means & Range & Means & Range & P-value \\
\hline Total Cholesterol & 206 & $154.5-320$ & 195.2 & $152-298.5$ & $\mathrm{P}>.05$ \\
HDL Cholesterol & 44.68 & $33.5-46.8$ & 45.5 & $34.7-48$ & $\mathrm{P}>05$ \\
LDL Cholesterol & 130.3 & $88.3-175.6$ & 106.3 & $43.5-165.7$ & $\mathrm{P}<.05$ \\
Triglyceride & 230.7 & $138.6-370.03$ & 173.9 & $131.8-355.5$ & $\mathrm{P}<.05$ \\
\hline
\end{tabular}

P-value reached by paired ' $t$ ' test

and triglyceride were significantly higher in case group $(\mathrm{P}<.05)$ than control group $(130.3-106.3 \mathrm{mg} / \mathrm{dl}$ and 230.7$173.9 \mathrm{mg} / \mathrm{dl}$ respectively) (Table-II). But HDL cholesterol level was $44.68 \mathrm{mg} / \mathrm{dl}$ in case group and $45.5 \mathrm{mg} / \mathrm{dl}$ is control group (Table-II) which was not statistically significant $(\mathrm{P}>.05)$.

\section{Discussion:}

This study was carried out to find the serum concentration of fasting lipid in stroke (ischaemic) patients and to compare it to age and sex matched control subjects to establish the lipid as a risk factor of ischaemic stroke.

This study has revealed the median plasma total cholesterol in cases was $206 \mathrm{mg} / \mathrm{dl}$ and that in the control group was $195.2 \mathrm{mg} / \mathrm{dl}$ which was statistically insignificant. In our study mild hypercholesterolemia was detected in case group, but in the study of other people sometimes significant hypercholesterolemia are detected in ischeamic stroke patients.

In our country Quraishi in 1987 and Latif et al. in 1990 showed direct relationship of ischaemic stroke with hypercholesterolemia and thus listed relationship with blood lipid i.e hyperlipidemia as a risk factor for ischaemic stroke. ${ }^{12}$

Mayer JS, Rogers RL, Mortel KF, Judd BW. in 1998 showed in their study that cerebral blood flow level were reduced among group of TIA patients with the elevated level of either cholesterol or triglyceride compared with the TIA patients with normal lipids levels. ${ }^{13}$
Cazzato g, Zorzoon M, and Monit F. in 1998 showed in their study that the mean total cholesterol concentration was significantly higher in male patients affected by TIA and cerebral infarction ${ }^{14}$.

Armin JG et al. in 2002 also showed in their study that hypercholesterolemia was particularly common in both microangiopathic stroke (44\%) and macroangiopathic stroke (41.4\%) and least frequent cardio embolism combined other aetiologies $(21.9 \%){ }^{15}$

In our study mean level of HDL-cholesterol is nearer to cases and control ( $44.08 \mathrm{mg} / \mathrm{dl} \& 45.5 \mathrm{mg} / \mathrm{dl}$ respectively). Duetill et al. in 2000 showed in their study of eighty eight age and sex-matched control with seventy nine patients. That patients had HDL-C and HDL-C/APO A 1 ratio were significantly lower than control. ${ }^{16}$

Albucer JF et al. in 2004 concluded in their study of serum lipids in young patients with ischaemic stroke, a case control study that low HDL-cholesterol was only serum lipid index to be associated to an increased risk of stroke in that population. $^{6}$

Though our small scale study have no correlation with these studies but in many other researcher's study showed that HDL- cholesterol is a risk factor of ischemic stroke.

Regarding LDL-cholesterol in our study, cases has significantly higher $(\mathrm{P}<0.05)$ LDL-cholesterol $(130.3 \mathrm{mg} / \mathrm{dl})$ than control $(106.3 \mathrm{mg} / \mathrm{dl})$.

Hachinski V et al. in 1996 showed that LDL-cholesterol $(153 \mathrm{mg} / \mathrm{dl}$ vs $130 \mathrm{mg} / \mathrm{dl})(\mathrm{P}=0.004)$ levels were significantly 
higher among the patients with atherothrombotic strokes and transient ischemic attacks than among the control subjects $^{17}$. In another study Lalaux P, Galanti L, and Janeant I. in 2004 showed in their case control study of lipids in ischaemic stroke subjects that a significant increase in the LDL-cholesterol level $(\mathrm{P}<.004)$ and a significant decrease in HDL-C $(\mathrm{P}=.001)$ were only observed in LVD (large vessel Disease). ${ }^{18}$

Triglyceride level was also significantly higher $(\mathrm{P}<.05)$ in case group $(230.7 \mathrm{mg} / \mathrm{dl})$ than control group $(173.9 \mathrm{mg} / \mathrm{dl})$ in our observations which has similarity with many other studies.

In a study of cholesterol and the risk of ischaemic stroke by Bowman TS, et al in 1998 showed that total cholesterol, HDL and triglyceride were not significantly associated with ischaemic stroke risk. ${ }^{19}$ But in later time researches have shown that high triglycerides - a type of blood fat are strong independent predictor of a person's risk for stroke. ${ }^{11}$ It is also shown that low density lipoprotein become smaller \& denser small, dense phenotype or pattern $\beta$ - is hyper triglyceridemia states. ${ }^{9}$ Besides this Morag NK, Eran C, Gold B. in 2002 showed that about a quarter of the patient of stroke had triglyceride level of $200 \mathrm{mg} / \mathrm{dl}$ and higher than control. ${ }^{11}$ Tame D, Koren-Morag N, Graff E, Goldbilatom V. in the year 2006 showed that patient experienced an ischaemic stroke/TIA had higher mean level of triglycerides, lower levels of HDL cholesterol and lower percentages of cholesterol contained in HDL cholesterol moiety (\%HDL, $\mathrm{P}<0.01$ for all). ${ }^{20}$

Bangladeshi people's main food stuff is rice and most our study populations (case and controls) takes rice almost 3 times a day. So we presumed that our people might have higher level of triglyceride. Though there is higher mean value of triglycerides in ischaemic stroke cases $(230.7 \mathrm{mg} /$ dl). than controls $(173.9 \mathrm{mg} / \mathrm{dl})$, but our presumption was that more higher value could be found in our study population.

Though it is well established fact that higher serum lipids are directly related with coronary artery disease but it remains still controversial about the relations between serum lipids and ischaemic stroke. ${ }^{21}$ But more recent studies (2006) showed some direct and indirect relationship of serum lipids with stroke. ${ }^{19}$ Beside these South Asian populations in the U.K. have a high percentage of coronary heart disease, central obesity (high waist to hip ratios), insulin resistance, non-insulin dependent diabetes, hypertension and high stroke mortality, but there is no good information on incidence. This seems to be due partly to genetic susceptibility (high serum lipoprotein levels) in these people potentiated by dietary and life style induced changes in lipid levels ${ }^{22}$.

Our study populations has also reflected above mentioned idea about the ischaemic stroke and lipid level, ie. higher lipid levels (total cholesterol, LDL-cholesterol and triglyceride) was found in ischaemic stroke patients than control people.

\section{Conclusion:}

As stroke is more preventable than to look for the cure. So, at present in the country like ours, need more effort to control the risk factors like lowering of serum lipid level to reduce the incidence of stroke. For this, simultaneous community screening program for dyslipidaemias with other controllable risk factors (smoking, hypertension, diabetes mellitus) on a large scale basis for middle aged to elderly group people may be an effective measure to reduce the incidence of stroke.

\section{Conflict of Interest : None}

\section{References:}

1. Smitah WS, Johnston SC, Easton JD, Cardiovascular disease. In: Kasper DL, Fauci AS, Long DL, Brainwald HE, L Stephen. and Jamsen LL, (eds). Harrison's Principles of Internal Medicine. $16^{\text {th }}$ ed. Vol-2, McGraw-Hill Medical Publishing Division, New York. 2005;2372-93

2. Mohammad QD. Course of the aging process. Bang Med J. 2003; 32:4, 68-69.

3. Mc Caron OM, Delong D and Alberts MJ. APO-E genotype as a risk factor for ischaemic cerebrovascular disease. Neurology. 1994;44:626-634.

4. Mohammad QD, Mannan MA, Fakir NH, Rahman HZ, Quarassi FA, Begum JA. Cerebral thrombosis and risk factors, Study of 12 cases. Bangladesh J Neuroscience. 1987;3:2,48-54.

5. Albucheer F J, Ferries J, Ruidavates J B, Chaumait GB, Perret PB, Cholvet F. Serum lipids in young Patents with ischaemic stroke a case control study. J.Neural Neurosurg. 2000;69:29-33(July).

6. Rahman M MD, Mosharraf AKM, Hossain P, Ismail M. Risk factor for stroke -a clinical study. BJM. 2003;14:2,3640 .

7. Robbins SL, Cotrain RS, Kumar V, Collins T. Disease of the blood vessels. In: Pocket companions to Robbins Pathologic Basis of dissease. Sixth ed. W.B. Saunders Company, Philadelphia, Pensylvinia. 1999;259-60.

8. Mayes PA, Botham KM, Rodwell VW. Harper's Biochemistry-26 $6^{\text {th }}$ ed. McGraw-Hill Companies, USA. 2003;205-18. 
9. B chanu. Hypertriglyceridemia; danger for the arteries. Cardiol Rev. 2002;10(3):163-72.

10. K Geurian, Pinson JB, Weast CW. The triglycerides connection in atherosclerosis. Stroke. 2003;34:105-110.

11. Morag NK, Eran C, Gold B. High blood triglycerides are independent risk factors for stroke. Circulation. 2002; 26: 6-7.

12. Latif ZA, Zaman SM, Ahad A, Rahim SA. Study of stroke between between normotensive and hypertensive NIDDM cases in BIRDEM. Dhaka, Bangladesh J Neuroscience. 1990; 6:52-59.

13. Mayer JS, Rgers RL, Mortel KF, Judd BW. Hyperlipidaemia is a risk factor for decreased cerebral perfusion and stroke. N Engl J Med. 1987;317:521-26.

14. Cazzato G, Zorzon M, Carraro N, Monit F. Dyslipidaemias and ischaemic cerebaral vasculopathy. Neurology. 1998;50:1694-98.

15. Armin JG, Christian W, Florian B, et al. Risk Factors, Outcome and Treatment in Subtypes of ischaemic stroke. Stroke. 2000;31:2616-22.

16. Deuti L, Cecchethi A, Annoui V, Merli MF, Ablondi F, Valanti G. The role of upie profile in determing the risk of ischaemic stroke in the elderly; a cose control study. J Cardiovasc Risk. 1999;6:223-28.

17. Hachiuski V, Graffagniuo C, Beaudny M, Burmierk G, Buck C, Donner A, Sence JD, et al. lipids and stroke: a paradox resolved. Arch Neroal. 1996 Apr; 53(4):303-8.

18. Laloux P, Galanti L, Jamart J. Lifids in ischaemic stroke subtypes. Acta Neurol Belg. 2004 Mar;104(1):13-9.

19. Bownaan TS, Sesso HD, Ma J, Kurth T, Kase CS, Stamfer MJ, Oaziamo JM. Cholesterol and the risk of ischaemic stroke. Neurology. 1998;50:196-03.

20. Tanne D, Koven-Morag N, Graff E, Goldbourt U. Blood lipids and first ever ischaemice stroke/transient ischaemic attack in the Beazafibrate infarction prevention (BIP) Registry: hightriglyceride constitute an independent risk factor. Circulation. 2001 Dec 11;104(29):2892-7.

21. Shahar E, Chambless LE, Rosmond WD, Bolan LL, Ballnating CM, Mc Corern PG, Sharretar P. Plasma lipid profile and incident of ischaemic stroke: the atherosclerosis risk in communities (ARIC) study. Storke. 1989;20:983-89.

22. Charles W. Stroke, transient ischaemic attacks and venous thrombosis. In: Donaghy M. Brain's disease of the nervous system. $11^{\text {th }}$ ed. Oxford University Press Inc., New York. 2001;776-80. 